\title{
THE EFFECTS OF VISCOUS HEATING AND THE PRESSURE-DEPENDENT VISCOSITY ON LIQUID FLOW IN MICROTUBES
}

\author{
Zhan-hua Silber-Li, Hai-hang Cui \\ LNM, Institute of mechanics, CAS, Beijing, China, lili@lnm.imech.ac.cn
}

\begin{abstract}
The flow characteristics of isopropanol in microtubes driven by a high pressure ranging from $1 \mathrm{MPa}$ to $30 \mathrm{MPa}$ are studied in this paper. The diameters of the microtubes are from $3 \mu \mathrm{m}$ to $100 \mu \mathrm{m}$. The Reynolds number ranges from 0.1 to 1000 approximately. From the present experimental results, two reverse trends of the normalized friction coefficient $\mathrm{C}^{*}$ are found for the various diameters. From the analysis of several possible factors, it may be seen that the pressure-dependence viscosity and viscous heating play the leading role. The relationship of viscosity versus pressure pointed out that the viscosity of most liquids, except the water, augmented with the increase of pressure. The analysis based on the energy equation turns out that pressure drop, specific heat, density, flow rate and heat resistance decide the average temperature rise due to viscous dissipation. Therefore, above two factors are treated as the function of pressure. An exponential function with the dependence of pressure is introduced into Hagen-Poiseuille (HP) equation to counteract the difference between experimental and theoretical values. Consequently, C* exhibits different trends which is decided by the relative importance of viscous heating and the pressure-dependent viscosity.
\end{abstract}

\section{INTRODUCTION}

The fluid flows in microtubes and microchannels have attracted much attention because of its prospective uses in Micro-Total-Analytical-System ( $\mu$ TAS), the cooling of computer chips, biochips and micropower generations etc [1,2]. Some available experimental data [3,4] indicate that the behaviors of liquid flows in microchannels can be well predicted with the continuum theory. However, some effects will show up with the decrease of characteristic dimension, such as the dependence of viscosity on pressure [5], wall slip [6] and electrical double layer (EDL) [7]. On the other hand, due to a high shear rate and a high driven pressure, the possible effect of viscous dissipation on the temperature field has to be considered. Because the viscosity is extremely sensitive to the temperature, the effect of viscous dissipation on the friction factor cannot be ignored. Recently, more studies [8-14] on the effect of viscous heating in microscale were reported. In the present paper, the flow characteristics of isopropanol in microtubes driven by a high pressure ranging from $1 \mathrm{MPa}$ to 30 $M P a$ are studied. The diameters of the microtube are from $3 \mu \mathrm{m}$ to $100 \mu \mathrm{m}$. The Reynolds number ranges from 0.1 to 1000 approximately. From the present experimental results, two reverse trends of the normalized friction coefficient $C^{*}$ are found due to the various diameters. From the analysis of several possible factors, it may be seen that the pressure-dependence viscosity and viscous heating play the leading role here. Consequently, C* exhibits different trends which is decided by the relative importance of viscous heating and the pressuredependent viscosity.

\begin{tabular}{|c|c|}
\hline \multicolumn{2}{|c|}{ NOMENCLATURE } \\
\hline Symbol & Description \\
\hline $\mathrm{C}^{*}$ & Normalized friction coefficient \\
\hline Cp & Specific heat \\
\hline d & Diameter of microtube \\
\hline $\mathrm{F}$ & Body force \\
\hline $\mathrm{L}$ & Length of microtube \\
\hline M & Mass \\
\hline $\mathrm{P}$ & Pressure \\
\hline $\mathrm{P}(\mathrm{x})$ & Pressure distribution function \\
\hline $\mathrm{p}_{\mathrm{n}}$ & Surface force \\
\hline $\mathrm{Q}$ & Flow rate \\
\hline q & Heat flux \\
\hline $\mathrm{R}_{\text {heat }}$ & Heat resistance \\
\hline $\operatorname{Re}$ & Reynolds Number \\
\hline $\mathrm{T}$ & Temperature \\
\hline $\mathrm{u}$ & Uncertainty \\
\hline $\mathrm{U}$ & Internal energy, \\
\hline $\mathrm{V}$ & Velocity \\
\hline $\mathrm{x}$ & Axial coordinate \\
\hline$\tau$ & Volume element \\
\hline $\mathrm{S}$ & Surface element \\
\hline$\alpha$ & Pressure-viscosity coefficient \\
\hline$\beta$ & Temperature-viscosity coefficient \\
\hline$\Delta \mathrm{P}$ & Pressure drop \\
\hline$\Delta \mathrm{P}(\mathrm{x})$ & Pressure drop distribution \\
\hline$\Delta \mathrm{T}$ & Temperature rise \\
\hline$\Delta \mathrm{T}(\mathrm{x})$ & Temperature rise distribution \\
\hline$\kappa$ & Thermal conductivity \\
\hline$\mu$ & Viscosity \\
\hline$\rho$ & Density \\
\hline Subscripts & \\
\hline 0 & Stand \\
\hline
\end{tabular}




$\begin{array}{ll}\text { app, } & \text { apparent } \\ \text { in } & \text { Microtube inlet } \\ \text { out } & \text { Microtube exit } \\ \text { aver } & \text { Average } \\ \text { w } & \text { Wall } \\ \text { exp } & \text { Experimental } \\ \text { HP } & \text { Hagen-Poiseuille theoretical } \\ \text { p } \mu & \text { Pressure-viscosity } \\ \text { T } \mu & \text { Temperature-viscosity }\end{array}$

\section{EXPERIMENTAL MEASUREMENT AND RESULTS}

\section{Measurement of friction coefficient and temperature rise}

In the case of steady laminar flow in a straight tube, the Navier-Stokes (NS) equation can be simplified as HP equation. The flow rate $Q_{H P}$ can be expressed as:

$$
Q_{H P}=\frac{\pi d^{4}}{128 \mu_{0} L} \Delta P
$$

where $d$ is the diameter, $L$ is the length, $\mu_{0}$ is the viscosity, $\Delta P$ is the pressure drop between the two ends of the microtube. When $P_{\text {out }}=0, \Delta P=P_{\text {in }}-P_{\text {out }}=P_{\text {in }}$. The normalized friction coefficient $C^{*}$ is defined as:

$$
C^{*}=\frac{(f \cdot \mathrm{Re})_{\exp }}{(f \cdot \mathrm{Re})_{H P}}=\frac{Q_{H P}}{Q_{\exp }}
$$

where $R e$ is Reynolds number, $f$ the friction coefficient and $Q_{\exp }$ the experimental flow rate.

Our experiment was carried out in a high-pressure microflow setup as shown in FIG.1. The high-pressure pump of $1 \sim 30 \mathrm{MPa}$ is used to drive the working liquids. The testing section consists of a tee connector, a pressure transducer, two thermocouples and a microtube. Polymicro Technologies Company provides the fused silica microtubes with a quoted accuracy of $\pm 20 \%$ for their inner diameters. The pressure transducer and one thermocouple are connected to the tee connector, through which the inlet pressure and temperature of the working liquid can be measured. Another thermocouple is placed at the end of microtube to measure the exit average temperature. One end of the microtube is linked to the tee connector with a mechanical seal and the other end is inserted into a capillary. The microtube is long enough to neglect the inlet and outlet effects. The working liquid passing through the microtube is measured using electrical balance when the diameter is larger than $20 \mu \mathrm{m}$. The flow rate can be obtained by the measurement of the liquid mass $\mathrm{M}$ and the time interval $\mathrm{t}$. Since the evaporation has a crucial effect, the capillary is inserted into the conical flask that is sealed with the lid. However, the flow rate is so tiny for the microtube smaller than $10 \mu \mathrm{m}$ and the interface displacement measurement is used instead of electrical balance. For the same reason, the exact temperature rise is difficult to obtain in microtube with the diameter smaller than $10 \mu \mathrm{m}$ and the temperature rise measurement is not conducted. The simple liquid with small molecules, isopropanol, is used in our experiments, which can be treated as Newtonian liquid when the critical shear rate $\gamma_{\mathrm{cr}}$ less than $10^{12}$. Generally, the uncertainty $u$ of a function is related with the variables measured in the experiments. From Eq.1and Eq.2, the uncertainty $u_{C^{*}}$ in $C^{*}$ is defined as:

$$
\frac{u_{C^{*}}}{C^{*}}= \pm \sqrt{\frac{16}{d^{2}} u_{d}^{2}+\frac{u_{\Delta P}^{2}}{\Delta P^{2}}+\frac{u_{\mu}^{2}}{\mu_{0}{ }^{2}}+\frac{u_{L}^{2}}{L^{2}}+\frac{u_{Q_{\exp }^{2}}}{Q_{\exp }{ }^{2}}}
$$

where $u_{i}$ in the radical sign is the uncertainty of the related parameter referring to the respective subscripts.

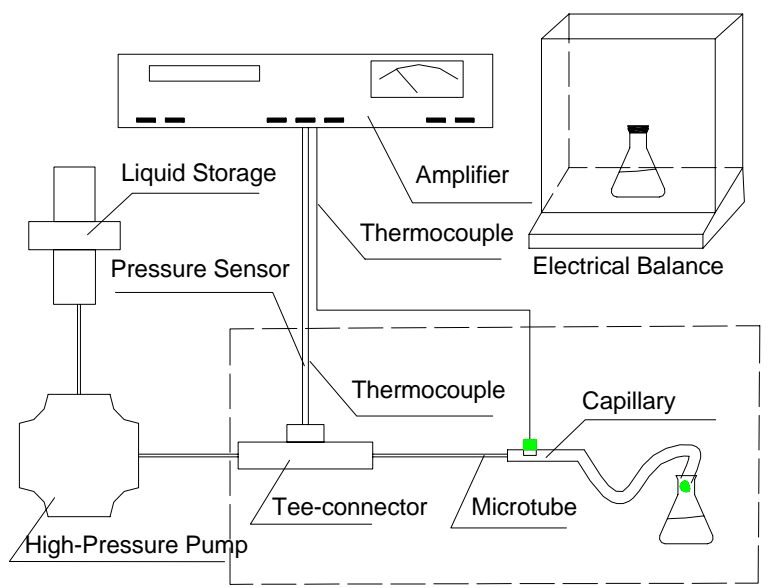

\begin{tabular}{|c|c|c|c|}
\hline Parameter & \multirow[t]{2}{*}{$\begin{array}{c}\text { Absolute } \\
\text { uncertainty }\end{array}$} & \multicolumn{2}{|c|}{$\begin{array}{c}\text { Relative } \\
\text { Uncertainty }\end{array}$} \\
\hline \multirow{6}{*}{$d$} & & $2.95 \mu m$ & $\pm 3.39 \%$ \\
\hline & \multirow{5}{*}{$0.1 \mu \mathrm{m}$} & $4.99 \mu \mathrm{m}$ & $\pm 2.00 \%$ \\
\hline & & $10.02 \mu \mathrm{m}$ & $\pm 1.00 \%$ \\
\hline & & $18.42 \mu \mathrm{m}$ & $\pm 0.54 \%$ \\
\hline & & $57.50 \mu \mathrm{m}$ & $\pm 0.17 \%$ \\
\hline & & $94.50 \mu \mathrm{m}$ & $\pm 0.11 \%$ \\
\hline$\Delta P$ & \multicolumn{3}{|c|}{ $\pm 0.3 \%$} \\
\hline$T$ & \multirow{2}{*}{\multicolumn{3}{|c|}{$\frac{ \pm 0.1 \mathrm{~K}}{+0.02 \mathrm{~mm}}$}} \\
\hline$L$ & \multirow{2}{*}{\multicolumn{3}{|c|}{$\begin{array}{c} \pm 0.02 \mathrm{~mm} \\
\pm 0.001 \mathrm{~g}\end{array}$}} \\
\hline$M$ & & & \\
\hline$t$ & \multicolumn{3}{|c|}{ $\pm 0.01 \mathrm{~s}$} \\
\hline
\end{tabular}

FIG.1. Schematic drawing of experimental setup

TABLE.1. Uncertainties of the experimental system

TABLE.2. Experimental parameters

\begin{tabular}{|c|c|c|}
\hline $\mathrm{d}(\mu \mathrm{m})$ & $\mathrm{L}(\mathrm{mm})$ & Total uncertainty \\
\hline 2.95 & 28.73 & $\pm 13 \%$ \\
\hline 4.99 & 55.02 & $\pm 8 \%$ \\
\hline 10.02 & 46.06 & $\pm 4 \%$ \\
\hline 18.42 & 143.01 & $\pm 3 \%$ \\
\hline 57.50 & 140.28 & $\pm 2 \%$ \\
\hline 94.50 & 1125.69 & $\pm 2 \%$ \\
\hline
\end{tabular}

The uncertainties of variables measured in the experiments are given in TABLE.1. The experimental results are presented as the arithmetic average values and the experimental uncertainty. The arithmetic average value is calculated from at least three measurements. The geometrical parameters, the ambient temperature and the total uncertainties are listed in TABLE.2. 
A detail experimental process can be found in our previous work [5].

\section{EXPERIMENTAL RESULTS AND ANALYSIS}

\section{Experimental Results}

In FIG.2 and FIG.3, the relationships of the normalized friction coefficient $C^{*}$ vs. the pressure drop $\mathrm{P}$ are given for each microtube, respectively. In order to study the change of $\mathrm{C}^{*}$, all data is normalized by the respective flow rate at low pressure about $5 \mathrm{MPa}$. From the present experimental results, two reverse trends of the normalized friction coefficient $C^{*}$ are found with the various diameters. Firstly, $\mathrm{C}^{*}$ decreases with the pressure increase in 50 and $100 \mu \mathrm{m}$ microtube in FIG.2. Secondly, C* for isopropanol in 3 20 $\mu$ m microtube increases significantly with the pressure in FIG.3. The experimental parameters are given in Table2. Note that the high-pressure pump provides a limited flow rate less than $1 \mathrm{~mL} / \mathrm{min}$. In order to obtain the experimental data at 25MPa, the $1125.69 \mathrm{~mm}$ microtube with largest diameter $100 \mu m$ is used. Even though, the pump can't work steadily at maximum pressure 25MPa and the pressure fluctuation is too big to be neglected. This may be a possible reason that the change of $C^{*}$ of $100 \mu \mathrm{m}$ microtube shows a strange trend.

The data of the exit average temperature rises are given in FIG.4. Three kinds of microtube (Polymicro Technologies), with the nominal diameters of 100,50 and $20 \mu \mathrm{m}$ are used. In order to compare the effect of diameter, three kinds of microtube have the same length, $\mathrm{L}=150 \mathrm{~mm}$. Because the flow rate for $10,5,3 \mu \mathrm{m}$ microtubes is too small, it is difficult to acquire believable measurement and no temperature measurement is conducted. Here, the data of temperature rise are plotted as a function of $\Delta \mathrm{P} / \rho \mathrm{C}_{\mathrm{P}}$ with the temperature unit $K$. For $100 \mu m$ microtube, only a few experimental points are obtained because of the limitation of the pump flow rate. From the present results, it is clear that the temperature rises of the larger diameter microtube are larger than that of smaller diameter microtube.

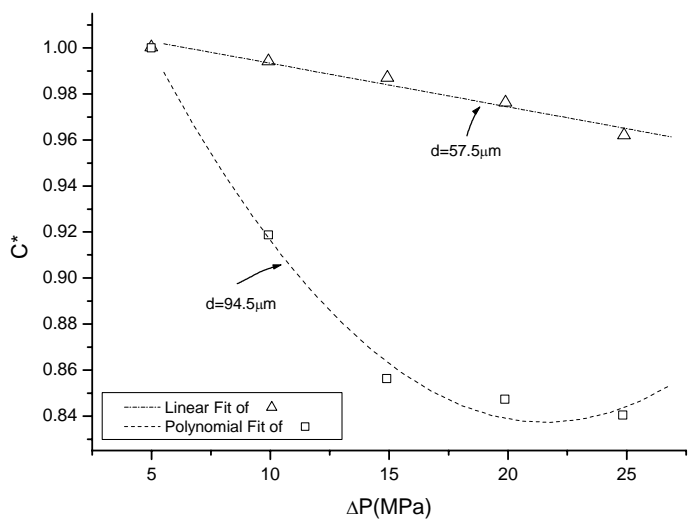

FIG.2. The normalized friction coefficient vs. pressure for isopropanol in 100, $50 \mu \mathrm{m}$ microtube

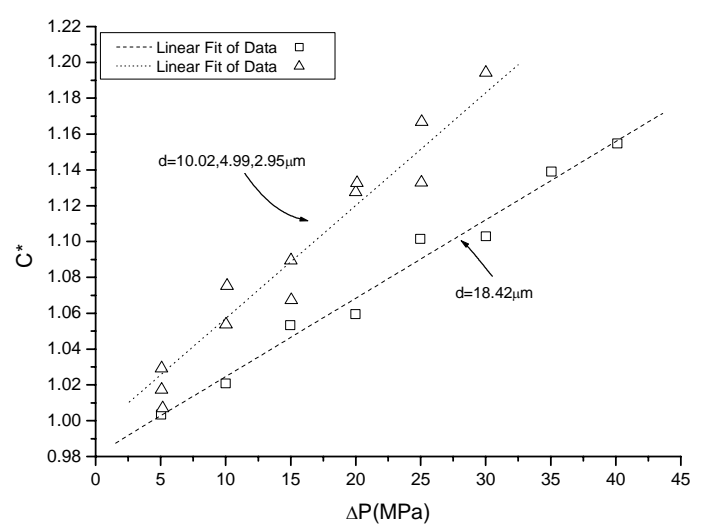

FIG.3. The normalized friction coefficient vs. pressure for isopropanol in 20,10, 5, $3 \mu \mathrm{m}$ microtube

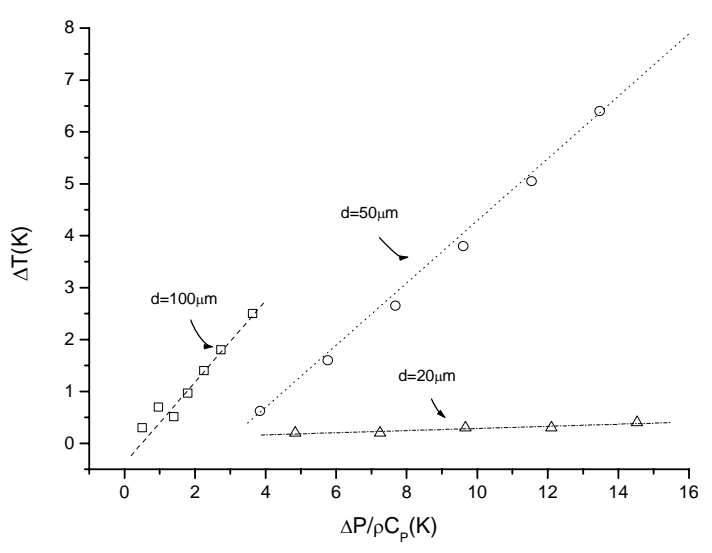

FIG.4. The exit average temperature rise vs. pressure in $100,50,20 \mu \mathrm{m}$ microtube with the same length $L=150 \mathrm{~mm}$

\section{ANALYSIS}

\section{Effects of the pressure-dependence viscosity}

According to P.W.Bridgeman[15], the relationship of viscosity versus pressure is,

$$
\mu_{\text {app }}=\mu_{0} e^{\alpha P}
$$

where $\alpha\left(7.9 * 10^{-9} \mathrm{~Pa}^{-1}\right)$ is the property coefficient, $\mu_{\text {app }}$ is the apparent viscosity due to high pressure. According to the HP equation, the variation of pressure $\operatorname{drop} \mathrm{dP}(\mathrm{x})$ along $\mathrm{dx}$ is,

$$
d P(x)=-\frac{128 \mu_{0} Q_{H P-P \mu} e^{\alpha P(x)}}{\pi d^{4}} d x
$$

Applying Eq.4, integrating Eq.5,

$$
\int_{P_{\text {in }}}^{P(x)} e^{-\alpha P(x)} d P(x)=-\frac{128 \mu_{0} Q_{H P-P \mu}}{\pi d^{4}} \int_{0}^{x} d x
$$

Then the pressure distribution is obtained, 


$$
P(x)=-\frac{1}{\alpha} \ln \left(\frac{128 \alpha \mu_{0} Q_{H P-P \mu}}{\pi d^{4}} x+e^{-\alpha P_{i n}}\right)
$$

Applying the condition $\mathrm{x}=\mathrm{L}, \mathrm{P}(\mathrm{x})=0$, we have,

$$
Q_{H P-P \mu}=\frac{\left(1-e^{-\alpha P_{i n}}\right)}{\alpha P_{i n}} \frac{\pi d^{4} P_{i n}}{128 \mu_{0} L}=\frac{\left(1-e^{-\alpha P_{i n}}\right)}{\alpha P_{i n}} Q_{H P}
$$

According to Taylor formula, the ratio of the revised flow rate $\mathrm{Q}_{\mathrm{HP}-\mathrm{p \mu}}$ to the flow rate $\mathrm{Q}_{\mathrm{HP}}$ is obtained,

$$
C^{*}=\frac{Q_{H P}}{Q_{H P-P \mu}} \approx 1+\frac{\alpha P_{i n}}{2}
$$

\section{Average temperature rise due to viscous dissipation}

The law of conservation of energy is expressed by [16],

$$
\begin{aligned}
\frac{\mathrm{d}}{d t} \int_{\tau} \rho\left(\mathrm{U}+\frac{\mathrm{v}^{2}}{2}\right) \mathrm{d} \tau & =\int_{\tau} \rho F \cdot v \mathrm{~d} \tau+\int_{s} p_{n} \cdot v \mathrm{~d} \mathrm{~S} \\
& +\int_{S} k \frac{\partial T}{\partial n} \mathrm{dS}+\int_{\tau} \rho q \mathrm{~d} \tau
\end{aligned}
$$

where, $\rho$ is the density, $U$ the internal energy, $v$ the flow velocity, $\mathrm{F}$ the body force, $\mathrm{p}_{\mathrm{n}}$ the surface force normal to surface, $\kappa$ the thermal conductivity of liquid, $T$ the temperature, $q$ the other heat flux, $d \tau$ and $d S$ are the elements of volume and surface. The term on the left side of Eq.10 is the change rate of entropy, including internal energy $U$ and kinetic energy $\mathrm{v}^{2} / 2$. The terms on the right side are the work of body force, the work of surface force, the heat flux through the wall (including conduction and the other heat flux, for example, radiation), respectively. The control volume is defined as the part within the tube wall and the entrance/exit. For a fully developed flow with the adiabatic boundary condition and negligible body force, the conductive heat flux and the other heat flux are equal to zero and only the work of surface force is considered. Eq.10 simplifies to,

$$
\int_{s} \rho \mathrm{U} v_{n} \mathrm{dS}+\int_{s} \rho \frac{v^{2}}{2} \mathrm{v}_{\mathrm{n}} \mathrm{d} S=\int_{s} p_{n} \cdot v \mathrm{~d} \mathrm{~S}
$$

When the pressure drop drives the flow, we obtain,

$$
\begin{gathered}
\int_{s} \rho U \mathrm{v}_{\mathrm{n}} \mathrm{ds}=\rho C_{p} Q\left(T_{\text {in }}-T_{\text {out }}\right)=\rho C_{p} Q \Delta T \\
E_{K} \sim \int_{0}^{r} \rho u(r) 2 \pi r d r \frac{u(r)^{2}}{2}=\frac{16 \rho Q_{H P}^{3}}{\pi^{2} d^{4}} \\
\int_{s} P_{n} \cdot v \mathrm{dS}=\left(P_{\text {in }}-P_{\text {out }}\right) Q=\Delta P Q
\end{gathered}
$$

where, $C_{p}$ is the specific heat, $v_{n}$ the velocity normal to the surface, $T_{\text {in }}$ and $T_{\text {out }}$ are the temperature at entrance and exit, respectively. Here, the changes of $\rho$ and $\mathrm{Cp}$ under high pressure are neglected since their changes are small quantity than the temperature rise. In order to simplify above equation, the comparison of the kinetic energy and the pressure work is conducted for different diameter mircotubes with the same length $\mathrm{L}=0.15 \mathrm{~mm}$ and $\triangle \mathrm{P}=1 M P a$. It can be seen than the kinetic energy is so small to be neglected when the diameter is less than $100 \mu \mathrm{m}$ in TABLE.3. In other words, it shows that, for the adiabatic flow in microtube, the work of surface force is equal to the change of internal energy due to viscous heating. Combining Eq.8 and Eq.14, the average temperature rise $\Delta \mathrm{T}$ is obtained as,

$$
\Delta \mathrm{T}=\Delta P / \rho \mathrm{C}_{\mathrm{p}}
$$

TABLE.3. Comparison of kinetic energy/pressure work

\begin{tabular}{|c|c|c|c|}
\hline $\mathrm{d}(\mu \mathrm{m})$ & $\mathrm{E}_{\mathrm{K}}$ & $\Delta \mathrm{PQ}_{\mathrm{HP}}$ & $\mathrm{E}_{\mathrm{K}} / \Delta \mathrm{PQ}_{\mathrm{HP}}$ \\
\hline 1 & $7.10 \mathrm{E}-21$ & $1.64 \mathrm{E}-10$ & $4.34 \mathrm{E}-11$ \\
\hline 10 & $7.10 \mathrm{E}-13$ & $1.64 \mathrm{E}-06$ & $4.34 \mathrm{E}-07$ \\
\hline 100 & $7.10 \mathrm{E}-05$ & $1.64 \mathrm{E}-02$ & $4.34 \mathrm{E}-03$ \\
\hline 200 & $1.82 \mathrm{E}-02$ & $2.62 \mathrm{E}-01$ & $6.94 \mathrm{E}-02$ \\
\hline
\end{tabular}

It is straightforward that $\Delta \mathrm{T}$ is uniquely determined by the pressure drop $\Delta \mathrm{P}$, density $\rho$, and specific heat $\mathrm{C}_{\mathrm{p}}$. Supposing the viscosity is only the function of temperature, the apparent viscosity is expressed as the function of pressure drop in the microtube with the adiabatic boundary condition,

$$
\mu(x)=\mu_{i n} e^{-\frac{\beta}{T_{i n}} \Delta T(x)}=\mu_{i n} e^{-\frac{\beta}{T_{i n}} \frac{\Delta P(x)}{C_{p} \rho}}
$$

here, $\beta$ is the property coefficient of the temperaturedependence viscosity, and $\beta=8.61$ for $\mathrm{T}_{\mathrm{in}}=293 \mathrm{~K}$. According to HP equation, the variation of pressure $\operatorname{drop} \mathrm{dP}(\mathrm{x})$ along $\mathrm{dx}$ is,

$$
d P(x)=-\frac{128 Q_{H P-T \mu} \mu_{i n} e^{\frac{\beta}{T_{i n}} \frac{P(x)-P_{i n}}{C_{p} \rho}}}{\pi d^{4}} d x
$$

The differential equation and its boundary condition are given,

$$
\left\{\begin{array}{c}
P(x)^{\prime}=A e^{B P(x)} \\
x=0, P(x)=P_{i n} \\
x=L, P(x)=0
\end{array}\right.
$$

here, $A=-128 Q_{H P-T \mu} \mu_{\text {in }} \psi^{\psi} / \pi d^{4}, \quad B=\beta / \rho C_{P}$ and $\psi=\beta P_{\text {in }} / \rho C_{P} T_{\text {in }}$. Solving this equation, the distribution of pressure is obtained,

$$
P(x) / P_{\text {in }}=1-\ln \left(1-\frac{x}{L}+e^{\psi} \frac{x}{L}\right) / \psi
$$

At the same time, the flow rate and the distributions of temperature and viscosity are obtained too,

$$
\begin{gathered}
Q_{H P-T \mu} / Q_{H P}=\left(e^{\psi}-1\right) / \psi \\
\mathrm{T}(\mathrm{x})=T_{i n}+\Delta T \ln \left(1-\frac{x}{L}+e^{\psi} \frac{x}{L}\right) / \psi \\
\mu_{\text {app }}(x) / \mu_{\text {in }}=\left(1-\frac{x}{L}+e^{\psi} \frac{x}{L}\right)^{-1}
\end{gathered}
$$

The average viscosity along the microtube is expressed as,

$$
\bar{\mu}=\frac{\int_{L} \mu_{\text {app }}(x) d x}{L}=\frac{\mu_{\text {in }} \psi}{e^{\psi}-1}
$$

The distribution of different parameters as a function of dimensionless length $\mathrm{x} / \mathrm{L}$ is given in FIG.5. 


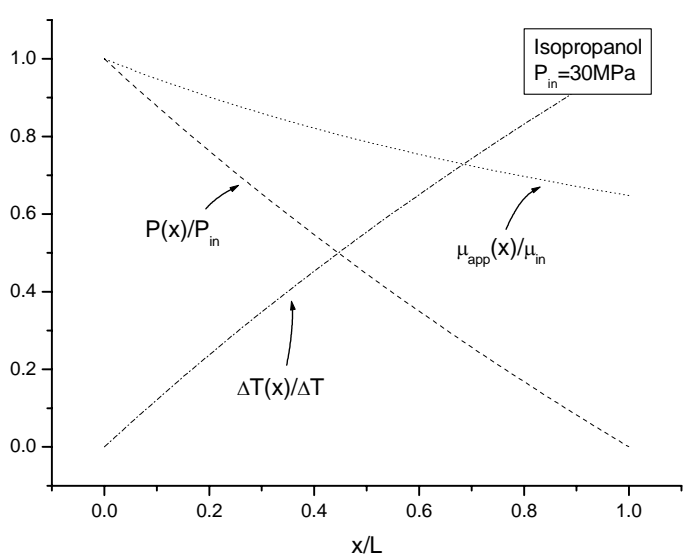

FIG.5. Distribution of pressure, temperature and viscosity along the microtube

According to Darcy-Weisbach equation, the friction coefficient is defined as,

$$
f=P_{\text {in }} /\left(\frac{\rho \bar{V}^{2}}{2} \frac{L}{d}\right)
$$

The average velocity in cross-section is obtained,

$$
\bar{V}=\frac{Q_{H P-P \mu}}{\pi d^{2} / 4}=\frac{\left(e^{\psi}-1\right)}{\psi} \bar{V}_{0}
$$

If we use the viscosity at entrance to define the Re number, $\operatorname{Re}_{\text {in }}=\rho d V / \mu_{\text {in }}, f . R e$ is,

$$
f \cdot \operatorname{Re}_{i n}=64 \psi /\left(e^{\psi}-1\right)
$$

If we use the average viscosity $\operatorname{Re}_{\mathrm{aver}}=\rho \mathrm{dV} / \mu_{\mathrm{aver}}$, then, f.Re is,

$$
f \cdot \operatorname{Re}_{\text {aver }}=64
$$

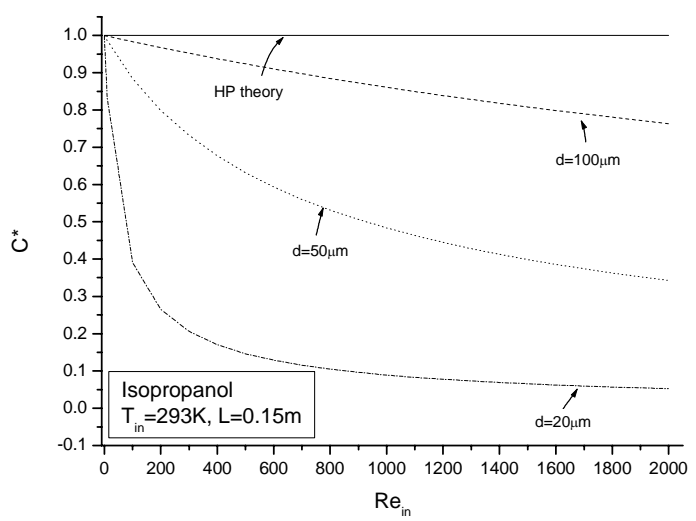

FIG.6. Relationship of $\mathrm{Re}_{\text {in }}$ versus $\mathrm{C}$ * for different diameter microtube with the same length $L=0.15 \mathrm{~m}$

According to the Eq.26, the relationship of $\mathrm{Re}_{\text {in }}$ versus $\mathrm{C}^{*}$ of isopropanol is plotted for different diameter microtubes with the same length $\mathrm{L}=0.150 \mathrm{~m}$ as shown in FIG.6. Here, it must be stressed that the change of $\mathrm{C}^{*}$ in FIG.6 is only an ideal condition due to the following two reason. Firstly, for a fixed length microtube with so small diameter, the high Re number means a very high pressure drop as the following equation,

$$
P_{i n}=\frac{\beta}{\rho c_{p}} \ln \left(\frac{32 \beta \mathrm{Le}_{i n} \mu_{i n}^{2}}{c_{p} \rho^{2} d^{3}}+1\right)
$$

For the isopropanol flow in the microtube with $d=20 \mu \mathrm{m}$, $L=0.15 \mathrm{~m}$ and $R e_{i n}=1000, P_{\text {in }}$ is about $260 \mathrm{MPa}$, which often is impossible in practice. However, for the same condition in $200 \mu \mathrm{m}$ microtube, $\mathrm{P}_{\text {in }}$ is $2.87 \mathrm{MPa}$. Secondly, the property coefficient $\beta$ would not be a constant when the temperature rise changes greatly. Even more, most property coefficients have to be redefined when the temperature is larger than the boiling point. So, Eq.26 give a depictive expression and its applicability is very limited.

If there exists the heat transfer through the tube wall, the law of conservation of energy Eq.10 is simplified as,

$$
\Delta P Q_{H P-T \mu}=\rho c_{p} \Delta T Q_{H P-T \mu}+\int_{0}^{L} \frac{\left(T(x)-T_{w}\right)}{R_{\text {heat }} L} d x
$$

It means that the work of surface force is equal to the change of internal energy and the heat flux through the tube wall. where $\mathrm{T}(\mathrm{x})$ is the distribution of average temperature in the crosssection, $T_{w}$ is the ambient temperature and $R_{\text {heat }}$ is the heat resistance, which includes the convective heat resistance of inner surface $R_{i}$, the conductive heat resistance through the tube wall $\mathrm{Ra}$ and the nature convective heat resistance of outer surface $\mathrm{R}_{0}$. All the microtubes have approximate outer diameter, $\mathrm{d}=350 \mu \mathrm{m}$. Among the three parts of heat resistances, the nature convective heat resistance $\mathrm{R}_{0}$ gives a main contribution and the difference of inner diameter has little influence on the total heat resistance $\mathrm{R}_{\text {heat }}$ as shown in Table.4. The total heat resistance $R_{\text {heat }}$ is $O\left(10^{2}\right)$ [17]. Supposing that $T_{w}$ is equal to the temperature at entrance, $\Delta \mathrm{T}(\mathrm{x})=\mathrm{T}(\mathrm{x})-\mathrm{T}_{\mathrm{in}}$. The temperature rise $\Delta \mathrm{T}$ at exit is, therefore,

$$
\Delta T=\frac{\Delta P}{\rho C_{p}} /\left(1+\frac{1}{c_{T} \rho C_{p} Q_{H P-T \mu} R_{\text {heat }}}\right)
$$

where, $\mathrm{c}_{\mathrm{T}}$ is $\Delta \mathrm{TL} / \mathrm{J} \Delta \mathrm{T}(\mathrm{x}) \mathrm{dx}\left(1<\mathrm{c}_{\mathrm{T}}<2\right)$. It is shown that Eq.30 is equivalent to Eq. 15 when $R_{\text {heat }} \propto \infty$. The temperature rise for

\begin{tabular}{|c|c|c|c|c|c|c|}
\hline & di & $\mathrm{R}_{\mathrm{i}}$ & $\mathrm{R}_{\mathrm{a}}$ & $\mathrm{R}_{\mathrm{i}}+\mathrm{R}_{\mathrm{a}}$ & $\mathrm{R}_{\mathrm{o}}$ & $\mathrm{R}_{\text {heat }}$ \\
\hline \multirow{3}{*}{ Isopropanol } & 20 & \multirow{3}{*}{5.36} & 2.00 & 7.36 & \multirow{3}{*}{126.39} & 133.75 \\
\hline & 50 & & 1.32 & 6.68 & & 133.08 \\
\hline & 100 & & 0.82 & 6.18 & & 132.58 \\
\hline
\end{tabular}
the different microtube with heat transfer boundary condition is plotted in FIG.7. The experimental data are compared with the Eq.30. It can be seen that the change of temperature rise shows a good agreement with the prediction, but all data are lower than the predicted value.

TABLE.4. Heat resistances of different microtubes

$\mathrm{do}=350 \mu \mathrm{m}, \mathrm{L}=0.15 \mathrm{~m}, \kappa_{\mathrm{air}}=0.0262 \mathrm{~W} / \mathrm{mK}, \kappa_{\text {Isopropanol }}=0.135 \mathrm{~W} / \mathrm{mK}$, $\kappa_{\mathrm{si}}=1.46 \mathrm{~W} / \mathrm{m} . \mathrm{K}, \mathrm{Nu}=3.66, \mathrm{Pr}_{\text {air }}=0.708$ 


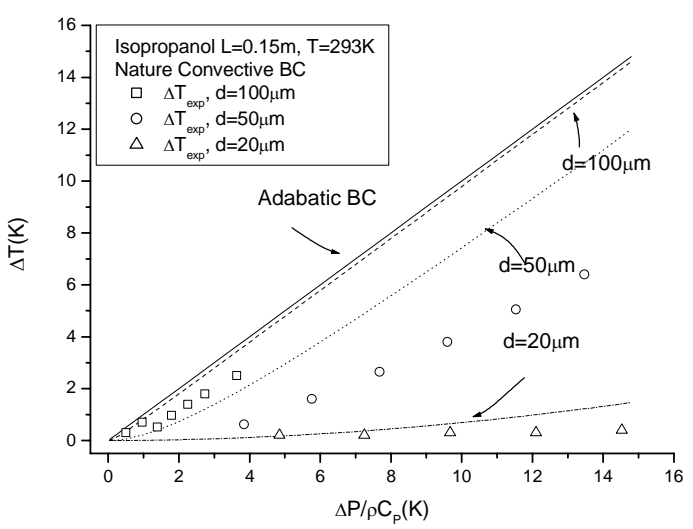

FIG.7. The comparison of the experimental average temperature rise and the Eq.30 prediction in different microtube with nature convective boundary condition

\section{Effects of the pressure-dependence viscosity and viscous heating}

Therefore, two factors must be considered into the flow of isopropanol. Firstly, the apparent viscosity of isopropanol will increase with the pressure increase according the pressuredependent viscosity function of Eq.4. Secondly, the apparent viscosity will decrease with the temperature increase that results from the viscous heating in Eq.15 and Eq.30. However, both factors are treated as a function of pressure. For the flow in microtube with adiabatic boundary condition, we have,

$$
\mu_{\text {app }}=\mu_{0} e^{\alpha P(x)+\frac{\beta\left(P_{i n}-P(x)\right)}{\rho c_{p} T_{i n}}}
$$

Through a similar analysis, the relationship is obtained for the present experiments,

$$
\frac{Q_{H P-P \mu-T \mu}}{Q_{H P}}=\frac{e^{\frac{\beta P_{i n}}{\rho c_{p} T_{i n}}}-e^{-\alpha P_{i n}}}{\alpha P_{i n}+\frac{\beta P_{i n}}{\rho c_{p} T_{i n}}}=\frac{e^{\psi}-e^{-\alpha P_{i n}}}{\alpha P_{i n}+\psi}
$$

For the flow in microtube with heat transfer, $\psi$ in above equation is replaced by $\psi^{\prime}=\beta \Delta \mathrm{T} / \mathrm{T}_{\mathrm{in}}$, approximately. The prediction using Eq.32 is given as shown in FIG.8. The comparison of the experimental C* and the Eq.32 prediction in different microtube with nature convective boundary condition comparesion is given in FIG.9. It is shown that the experimental $\mathrm{C}^{*}$ have the similar trend with theoretical prediction. However, the difference is obvious, for example, for $100 \mu \mathrm{m}$ microtube, the $\mathrm{C}^{*}$ is smaller than the model prediction. Above equation is only a one-dimensional model and the distribution in the cross-section has to rely on the numerical computation. To ignore the entrance/exit effect may results in an inaccurate prediction. Although, it is convenient to predict the trends of the change of normalized friction coefficient and flow rate.

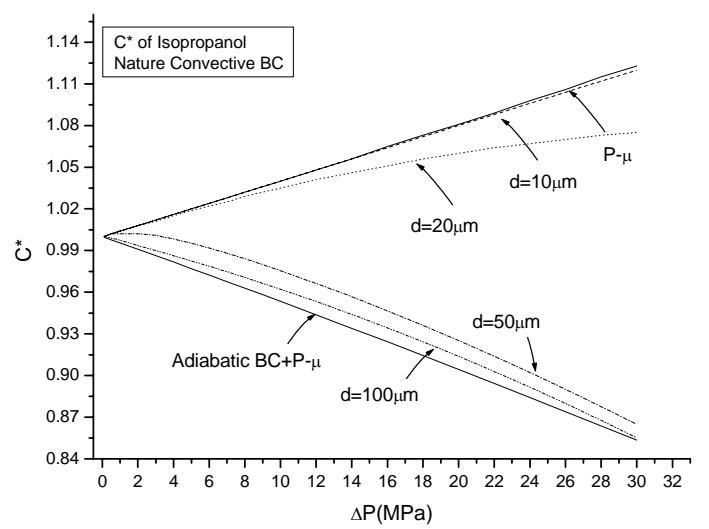

FIG.8. $C^{\star}$ as the function of pressure drop for isopropanol flow in different microtubes

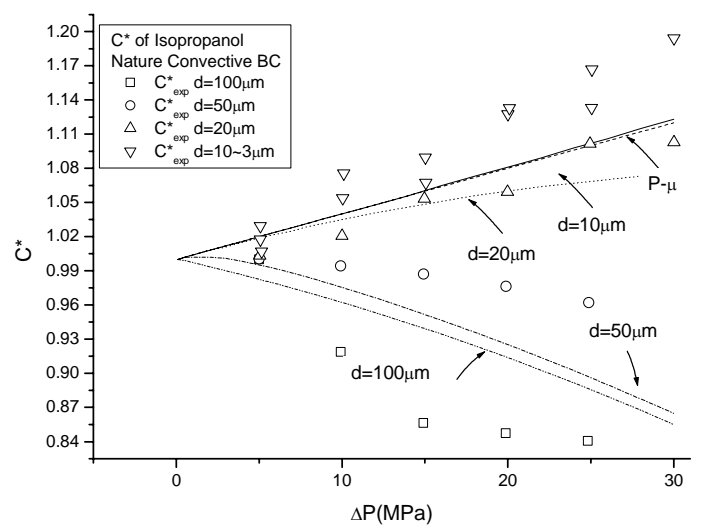

FIG.9. The comparison of the experimental $C^{\star}$ and the Eq.32 prediction in different microtube with nature convective boundary condition

\section{CONCLUSION}

The flow characteristics of isopropanol in microtubes driven by a high pressure ranging from $1 \mathrm{MPa}$ to $30 \mathrm{MPa}$ are studied in this paper. The diameters of the microtube are from $3 \mu \mathrm{m}$ to $100 \mu \mathrm{m}$. The Reynolds number ranges from 0.1 to 1000 approximately. The normalized friction coefficients and the exit temperature are measured under ambient temperature. The results indicate that:

I. Two reverse trends of the normalized friction coefficient $\mathrm{C}^{*}$ are found due to the various diameters. Firstly, $\mathrm{C}^{*}$ for isopropanol in 3 20 $\mu \mathrm{m}$ microtube increases significantly with the pressure. Secondly, in 50 and $100 \mu \mathrm{m}$ microtube, $\mathrm{C}^{*}$ decreases significantly with the pressure increase.

II. The exit average temperature rise increases with the pressure increase for all microtube. And, for the larger diameter microtube, the temperature rises are larger than that of smaller microtubes.

III. The pressure-dependence viscosity and viscous heating play the leading role here. $C^{*}$ exhibits different trends which is decided by the relative importance of viscous heating and the pressure-dependent viscosity. 
IV. For the adiabatic boundary condition, the average temperature rise due to viscous dissipation depends only on the pressure drop, specific heat and the density of the test liquids. If there exists heat transfer, besides three parameters mentioned above, flow rate and heat resistance also decide the temperature rise.

V. The experimental results can be well predicted by a simplified one-dimensional model combining the effects of viscous heating and the pressure-dependent viscosity.

\section{ACKNOWLEDGMENTS}

The author expresses their thanks to Chinese Academy of Sciences Major Innovation project (KJCX2-SW-L2) and the National Natural Science Foundation of China (10272107) for their supports to this research.

\section{REFERENCES}

1. Ho Chih-Ming and Tai Yu-Chong, "Micro-electromechanical-systems (MEMS) and fluid flows, " Annu. Rev. Fluid Mech 30, 579(1998).

2. Gad-el-Hak M, in Handbook of MEMS (CRC Press, Boca Raton, 2001).

3. Sharp, K.V., Adrian, R. J., Transition from laminar to turbulent flow in liquid filled microtubes, Experiments in fluids, 36(2004), 741-747

4. Li Zhanhua and Cui Haihang, Proceeding of experiments about liquid flow through micro-tubes, Inter. J. of Nonlinear Sci. And Num. Simulation, 3 42002, 577,.

5. Cui HH, Silber-Li ZH, Zhu SN, Flow characteristics of liquids in microtubes driven by a high pressure, Physics of fluids, 16 (5): 1803-1810, 2004

6. Chang-Hwan Choi, K. Johan A. Westin, and Kenneth S. Breuera, Apparent slip flows in hydrophilic and hydrophobic microchannels, Physics of fluids, 15(10), 2898-2902, 2003

7. Dongqing Li, Electro-viscous effects on pressure-driven liquid flow in microchannels, Colloids and Surfaces A:
Physicochemical and Engineering Aspects, 195 (2001) 35-57

8. Morini GL, Spiga M, Tartarini P, Laminar viscous dissipation in rectangular ducts, International Communications in Heat and Mass transfer 25(4), 551560, 1998

9. C.P. Tso, S.P. Mahulikar, Experimental verification of the role of Brinkman number in microchannels using local parameters, International Journal of Heat and Mass Transfer 43 (2000) 1837-1849

10. C.P. Tso, S.P. Mahulikar, The role of the Brinkman number in analysing flow transitions in microchannels. International Journal of Heat and Mass Transfer 42(1999), 1813-1833

11. J. Judy, D. Maynes, B.W. Webb. Characterization of frictional pressure drop for liquid flows through microchannels. International J.Heat and Mass transfer 45(2002), 3477-3489

12. J.Koo, C. Kleinstrruer, Viscous dissipation effects in microtubes and microchannels, Int. J. of heat and mass transfer, 47(2004), 3159-3169

13. Junemo Koo and Clement Kleinstreuer. Liquid flow in microchannels:experimental observations and computational analyses of microfluidics effects J. Micromech. Microeng. 13 (2003) 568-579

14. B Xu, K T Ooi, C Mavriplis and M E Zaghloul, Evaluation of viscous dissipation in liquid flow in microchannels. J. Of micromechanics and microengineering, 13(2003) 53-57

15. P.W.Bridgman, in the physics of high pressure, (G.Bell and Sons Ltd, 1952).

16. Landau \& Lifshitz, in Fluid Mechanics, Pergamon Press, 1987

17. Schaum's outline of theory and problems of heat transfer, Second editions, Donald Pitts, Leighton Sissom. McGrawHill Companies, Inc. 